\title{
Full-spectrum sustainability: an alternative to fisheries management panaceas
}

\author{
$\underline{\text { Paul Folev }}^{1,2}, \underline{\text { Evelyn Pinkerton }}^{1,3}, \underline{\text { Melanie G. Wiber }}^{1,4}$ and Robert L. Stephenson $^{1,5}$
}

ABSTRACT. This introduction to the special feature describes the development and application of a "full-spectrum sustainability" evaluation framework that emerged from a transdisciplinary research process. The framework and corresponding case studies described in this paper originated in the work of a Canadian Fisheries Research Network project that sought to enhance fisheries management by including diverse social-ecological considerations in fisheries management evaluation. The first section discusses the tendency of sustainability evaluation frameworks in fisheries to focus on ecological and economic considerations and introduces the Canadian Fisheries Research Network's four pillar approach, which includes ecological, economic, social and cultural, and institutional/ governance categories. To illustrate the comprehensive nature of this framework, the second section provides a comparison of the framework with elements in the United Nation's Sustainable Development Goals. The third section provides an overview of the eight papers in this special feature that explore the development and application of full-spectrum sustainability. The conclusion synthesizes some key findings, highlighting four overall critical and ongoing challenges associated with advancing full-spectrum sustainability evaluation in Canada and elsewhere: the politics of transdisciplinary research; integrating social considerations into management agencies reluctant to move beyond ecological and economic considerations; dynamic and diverse issues involved in supporting robust and inclusive governance processes; and translating technical frameworks into usable practical instruments for different societal actors.

Key Words: evaluation; fisheries; integrated management; sustainability; sustainable development

\section{INTRODUCTION}

Over the past half century, fisheries management has been the focus of significant theoretical critique (Jentoft and Chuenpagdee 2009). Fisheries managers now face the combined demands for an ecosystem approach to management (FAO 2003, Fletcher et al. 2010), market and environmental NGO pressure for thirdparty certification assessments (Foley 2013), an evolving set of policies related to sustainability (Kofinas and Chapin 2009, Chapin et al. 2010, Bond and Morrison-Saunders 2011), and the growing requirement to incorporate fishing-dependent communities, harvesters' organizations, and other stakeholders in the management decision-making process and in the sharing of stewardship responsibility (Pinkerton 2003, Armitage et al. 2009, Plummer et al. 2012, 2013, Pinkerton et al. 2014). Fisheries management has also been challenged to move beyond the tendency to focus exclusively on threats to fish stocks and a narrowly conceived perspective on economic viability by incorporating fundamental social issues of fairness, ethics, and justice in the human dimensions of fisheries management in areas such as the distribution of opportunities and benefits (Ommer 2000). In addition, as fisheries increasingly share the waters with other sectors and industries, fisheries management is also challenged to incorporate considerations of other relevant activities in the marine environment in more holistic integrated management (IM) approaches (Charles et al. 2010, Stephenson et al. 2019a). This evolution has resulted in the consideration of fisheries as part of social-ecological systems (Ommer et al. 2012) with a broad spectrum of objectives and requiring a different, interdisciplinary concept of sustainability that is very much broader than those focused on narrow conservation and economic objectives (for more holistic analyses, see Breslow et al. 2016,
Olsson and Ness 2019). Those seeking to adjust policies and decisions to multiple objectives and dimensions of sustainability must also overcome the persistent influence of powerful management panaceas, formulaic policy prescriptions such as individual transferable quotas and marine protected areas purported to solve problems in any context (Pinkerton and Davis 2015, Young et al. 2018). Shifting from simplistic formulaic to more complex and comprehensive management approaches remains mostly aspirational.

One approach to moving beyond simple policy prescription panaceas toward more comprehensive approaches involves multilevel auditing, assessment, evaluation, diagnosis, or use of frameworks (Ostrom and Cox 2010) for different contexts in fisheries management. These can be based on multiple objectives and subjected to qualitative and quantitative measures of success (Dahl 2012, Davis et al. 2012). A crucial factor in enhancing the legitimacy and effectiveness of such approaches involves the use of a transdisciplinary, coproduction approach that includes a strong empirical case study application to test and refine approaches. To create comprehensive evaluative frameworks, for example, Young et al. (2018) call for (i) the creation of transdisciplinary working groups that bring together academics, decision makers, and stakeholders to develop institutional diagnostic checklists that can draw on the extensive knowledge of different stakeholders and perspectives and (ii) the development of corresponding case narratives that go beyond simplistic narratives to highlight the importance of considering context (Young et al. 2018).

In this paper we describe the development of a comprehensive, "full-spectrum sustainability" approach that utilized such a

${ }^{1}$ Canadian Fisheries Research Network, ${ }^{2}$ Environmental Policy Institute, School of Science and the Environment, Memorial University of Newfoundland (Grenfell Campus), ${ }^{3}$ School of Resource and Environmental Management, Simon Fraser University, ${ }^{4}$ Department of Anthropology, University of New Brunswick, ${ }^{5}$ Department of Fisheries and Oceans (St. Andrews Biological Station) and Department of Biology, University of New Brunswick 
transdisciplinary research process with corresponding case studies, which are published in this special feature. The papers collected in this volume are representative of the full-spectrum sustainability evaluation framework and case studies of the Canadian Fisheries Research Network (CFRN; Thompson et al. 2019) project and how they (individually and together) advance fisheries evaluation and diverse ecological, social/cultural, economic, community, and institutional considerations in management. This paper introduces this special feature, which provides more detailed treatment of results and conclusions of two synthesis papers published elsewhere (Stephenson et al. 2018, 2019a).

\section{FULL-SPECTRUM SUSTAINABILITY AND THE CANADIAN FISHERIES RESEARCH NETWORK}

The practical application of the concept of sustainable development and sustainability is complex, contradictory, and fragmented, and is a source of both confusion and creativity (Lélé 1991, Meadowcroft 2000, Kates et al. 2005). Since the 1990s, sustainable development has often been understood to consist of three components: environmental protection, economic development, and social development (Kates et al. 2005). However, subsequent development of sustainability constructs has evolved without universal agreement on the details of the three components, and the practical development of evaluation and auditing frameworks for sustainability tend to prioritize particular elements and understandings. In fisheries, although sustainability is increasingly incorporated into international and national policy commitments, specific fisheries policy and management frameworks have continued to focus on conservation of fish stocks and marine environments, often to the exclusion of social considerations (Ommer 2000, Urquhart et al. 2013, Stephenson et al. 2017). Environmental nongovernmental organizations (NGOs) and market actors in the sustainable seafood movement, which use ranking systems, buying guides, traceability initiatives, certification programs, and various initiatives that combine one or several of these instruments (Jacquet and Pauly 2007, Parkes et al. 2010, Konefal 2013), have also tended to focus on conservation of fish stocks and marine ecosystems and not meaningfully engage with social dimensions (Ponte 2012, Micheli et al. 2014), a factor driving the emergence of alternative eco-certifications that incorporate ethical and social justice principles and criteria (Foley 2019). Some governmental and intergovernmental agencies, NGOs, fish harvester groups, and academic researchers have begun to develop tools to integrate social development dimensions into fisheries management, assessment, and marketing systems (Brooks et al. 2015, Symes and Hoefnagel 2010, Micheli et al. 2014, Kittinger et al. 2017, Stephenson et al. 2019b, Witter and Stoll 2017, Foley 2019). However, these initiatives also tend to be fragmented and little empirical research has been conducted to compare these assessment frameworks with actual fisheries and seafood contexts.

The research on which this special feature is based emerged from an innovative transdisciplinary research collaboration in Canada among fish harvesters, academic researchers, and government scientists (2010-2016) called the Canadian Fisheries Research Network (CFRN). The network was novel in its attempt to define requirements of multiple dimensions of sustainability in the Canadian context, its transdisciplinary and practical orientation linked to improving decision making, and its combining of conceptual development and practical testing through iterative framework processes and case studies (Stephenson et al. 2019a, Thompson et al. 2019). The network brought together fishing fleets, academics, and government to undertake coconstructed research on themes identified by industry to be critical to management. One project of this network, CFRN Project 1.1, focused on developing enhanced knowledge for an evolving fisheries management regime. Project 1.1 established an inclusive working group to develop a comprehensive framework for fishery evaluation that would redress a significant lacuna in "report card" approaches (Millennium Ecosystem Assessment 2005, Dahl 2012, Ommer et al. 2012, Pintér et al. 2012). The objective was to expand the established ecological tool kit to also include economic, social, and institutional/governance aspects (Triantafillos et al. 2014, Hicks et al. 2016). Graduate students and other members in the network undertook a series of case studies aimed especially at providing substance to the generally neglected social and institutional/governance considerations. The CFRN thus presented an opportunity to approach fisheries sustainability in a comprehensive way, through a transdisciplinary, coproduction method linking researchers from diverse fields with industry and government, and combining this approach with the identification of research objectives and case studies that "tested" framework development in empirical contexts.

The transdisciplinary process used by the CFRN resulted in a definition of full-spectrum sustainability that accounts for the diversity of relevant considerations of social-ecological systems. As part of the process, the group defined sustainable fisheries thus: "A sustainable fishery respects the ecological integrity of the ocean and its resources; is ethical, responsibly governed, economically viable and technologically appropriate; supports communities; draws on local culture, heritage, and diverse knowledge systems; and enhances health, wellbeing and the public good" (Stephenson et al. 2019a:482). The research and deliberation of the CFRN included a review of policies and international agreements relevant to Canada, the literature, and the combined experience of the team. The conclusion was that full-spectrum sustainability must be defined as having four pillars: ecological, economic, social-cultural, and institutional or governance. We accept that there are diverse perspectives on how to classify and to group objectives. The United Nations, for example, often defines sustainability along three pillars: economic development, social development, and environmental protection (e.g., Asche et al. 2018), and it has become common to talk of a "triple bottom line" (e.g., Elkington 2013). The major point of contention is whether institutional or governance objectives are a fourth pillar or perhaps an overarching lintel (Fig. 1). We argue that including governance as the fourth pillar is supported by increasing attention to influential institutional norms and practices, such as good management structures, effective decision making approaches, and legal obligations (including to Indigenous peoples), as well as by research showing that effective governance is often the weak link in achieving sustainability (Levin et al. 2016).

CFRN's definition of a sustainable fishery and its four-pillared approach to full-spectrum sustainability is rooted in the project's analysis of Canadian fisheries policies and international agreements. The project team reviewed these policies and 
Fig. 1. Two perspectives on full spectrum sustainability.

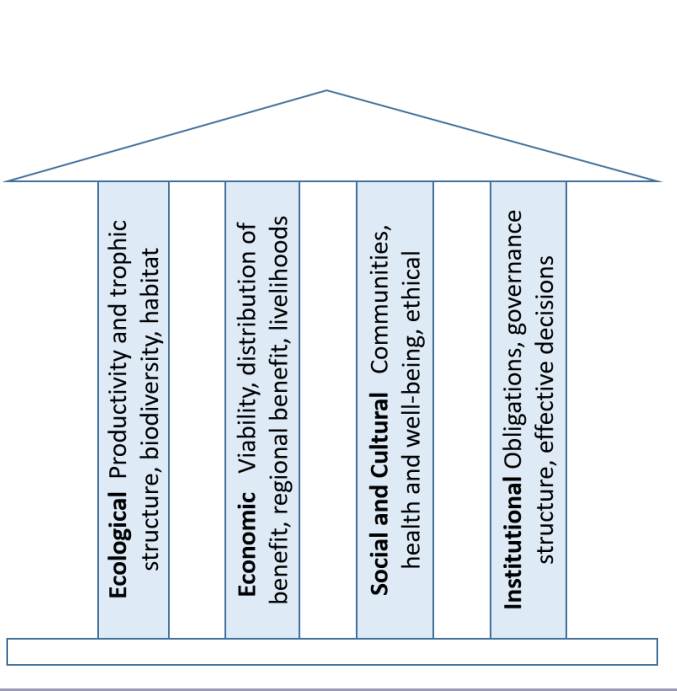

agreements and identified lists of objectives corresponding to the four pillars of sustainability. The objectives were then used as the basis for workshops and deliberations aimed at developing lists of specific elements and indicators within the four pillars. After several iterations of our framework, the resulting full-spectrum sustainability framework includes ecological, social, economic, and institutional candidate objectives for fishery planning, management, and evaluation. Further, each of the four categories offer candidate performance indicators that allow practical implementation (Stephenson et al. 2019a).

\section{FULL-SPECTRUM SUSTAINABILITY AND THE SUSTAINABLE DEVELOPMENT GOALS}

To illustrate the scope of the CFRN's approach to full-spectrum sustainability, it is helpful to compare it to elements of the Sustainable Development Goals (SDGs) of the UN 2030 Agenda for Sustainable Development adopted in 2015 (United Nations 2018). Although not restricted to fisheries, the SDGs are intended to link a comprehensive suite of aspects related to a sustainable future across sectors, and are indicative of international thinking about the scope of sustainability. Table 1 provides a comparison of SDG targets with elements (candidate objectives) of the CFRN framework. All of the CFRN framework elements are contained in the UN SDGs. The SDG's that are not directly identified in the CFRN framework are focused on terrestrial activities and general societal aspects (such as poverty, hunger, education, and energy use) that go beyond fisheries or other single sectors. The SDGs give clear indication of the need to consider the institutional aspects that make up the CFRN's fourth pillar.

\section{CANADIAN FISHERIES RESEARCH NETWORK EXPLORATION OF FULL-SPECTRUM SUSTAINABILITY}

The CFRN team recognized the importance of not treating comprehensive evaluation frameworks as panaceas and instead incorporated nuanced empirical analyses (Young et al. 2018). The development of the framework used an iterative process in which preliminary drafts of the framework informed the development

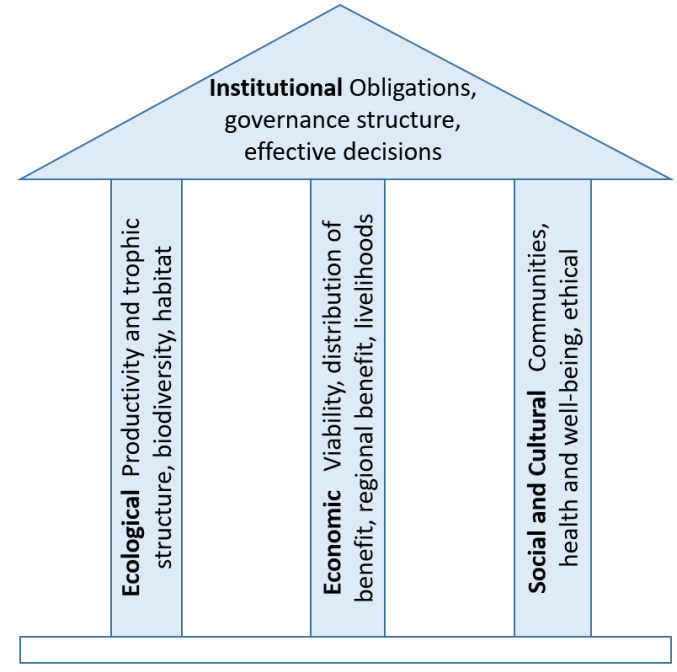

of initial sets of empirical case study research (Stephenson et al. 2019a). Presentations of findings from these early case studies informed workshops and discussions aimed at refining and finalizing the framework (e.g., Angel et al. 2019). This special feature contains eight papers that together illustrate the complexities of the development and application of the framework.

Angel et al. (2019) describe the development of an iteration of the sustainability indicator framework that supports a comprehensive, full-spectrum evaluation across three domains or high-level fields: governance, ecological, and socioeconomic. Evolving alongside the CFRN research process, this framework consists of a three-level, hierarchical structure of (1) domains, (2) dimensions, and (3) elements. Dimensions are the broad subject headings within each of the domains; they are used to organize conceptually similar elements, which comprise the third level of the hierarchy. For example, the governance domain contains three dimensions (institutional arrangements, decision-making process, decision outcomes), and in turn, the decision-making process dimension contains six elements (collaborative, transparent, inclusive, predictable, flexible, accountable). The framework thus provides a structure to facilitate the process of identifying objectives through a bottom-up approach in specific contexts. Indicators relevant to those specific contexts are to be identified and directly tied to the objectives in that particular instance. These fishery appropriate indicators can then help users to monitor, assess, and understand the impacts of human activities, and the effectiveness of management measures in achieving management objectives. This approach allows users of the sustainability indicator framework to do three things: (1) comprehensively and routinely identify relevant objectives and indicators; (2) systematically address each of the three domains without prioritizing any one domain over another; and (3) integrate multiple domains outside their areas of expertise, into a specific management program, project, or scheme. Finally, this paper illustrates that the sustainability indicator framework is both specific and flexible enough to be used across a range of fisheries management contexts. 
Table 1. Comparison of elements of the Canadian Fisheries Research Network (CFRN) framework for comprehensive evaluation of sustainable fisheries with major targets of the UN Sustainable Development Goals (SDGs).

\begin{tabular}{|c|c|}
\hline CFRN Framework element & UN SDG Targets \\
\hline \multicolumn{2}{|l|}{ Ecological } \\
\hline -productivity and trophic structure & SDG \#14 Life below water \\
\hline -biodiversity & SDG \#14 Life below water \\
\hline -habitat and ecosystem integrity & SDG \#14 Life below water \& SDG \#13 Climate action \\
\hline \multicolumn{2}{|l|}{ Economic } \\
\hline •financial value and viability & SDG \#8 Decent work and economic growth \\
\hline -distribution of access and benefits & SDG \#10 Reduced inequalities, SDG \#5 Gender equality \\
\hline •regional economic benefits & SDG \#9 Industry, innovation and infrastructure \\
\hline •livelihoods & SDG\#9 Industry, innovation and infrastructure \\
\hline \multicolumn{2}{|l|}{ Social and cultural } \\
\hline •sustainable communities & SDG \#11 Sustainable cities and communities \\
\hline •health and well-being & SDG \#3 Good health and well-being \\
\hline •ethical fisheries & SDG \#12 Responsible consumption and production \\
\hline \multicolumn{2}{|l|}{ Institutional } \\
\hline -obligations to law and Indigenous Peoples & SDG \#16 Peace, justice and strong institutions \\
\hline -good governance structure & $\begin{array}{l}\text { SDG \#16 Peace, justice and strong institutions, SDG\# } 17 \text { Partnerships for the } \\
\text { goals }\end{array}$ \\
\hline \multirow[t]{2}{*}{ •effective decision making processes } & SDG \#16 Peace, justice and strong institutions \\
\hline & $\begin{array}{l}\text { SDGs not directly linked to CFRN framework: SDG \#1 No poverty, \#2 Zero } \\
\text { hunger, \#4 Quality education, \#6 Clean water and sanitation, \#7 Affordable } \\
\text { and clean energy, \#15 Life on land }\end{array}$ \\
\hline
\end{tabular}

Jones and Stephenson (2019) explore potential application of the CFRN framework in practical management planning in the Bay of Fundy in eastern Canada. They first compare the scope of the CFRN framework with a set of community values criteria (CVC) developed after considerable public consultation by the Southwest New Brunswick Marine Resources Planning Initiative (later the SWNB Advisory Committee). Although the two frameworks share several features (especially in that they both emphasize the use of social performance indicators rather than the traditional ecological or economic criteria), the CFRN framework is more comprehensive in explicitly recognizing institutional or governance objectives as well. The paper goes on to compare the implications of considering the CFRN and CVC frameworks in evaluation of management plans for the herring (Clupea harengus) fishery and the recovery of the North Atlantic right whale (Eubalena glacialis) on the east coast. This evaluation demonstrates that the management plans are strong in their attention to ecological objectives but have gaps in the spectrum of considerations in current management planning, especially in relation to social, economic, and governance considerations. The authors propose that full-spectrum sustainability frameworks can provide, and should be used routinely as the basis for, analysis of policies and management plans, engagement and discussion among stakeholders in participatory governance, comparison of alternative management scenarios, and the generation of advice. Use of full-spectrum sustainability frameworks will allow better decisions on coastal activities that demand consideration of diverse social-ecological contexts and objectives.

Recognizing that third party market certification is becoming increasingly influential in the changing landscape of management, and that there is a need to integrate coastal management and to consider consistent management objectives across sectors, Mussells and Stephenson (2020) use the CFRN framework as a lens with which to compare certification schemes for three sectors (fisheries, aquaculture, and forestry) of relevance to activities in southwest New Brunswick. This paper reveals (1) that the three certification schemes differ in the scope of their objectives in spite of having similar origins, (2) that a number of CFRN framework elements are not addressed in the certification schemes, and (3) that the certification scheme that most closely matches the CFRN framework is from the forestry sector. The Marine Stewardship Council (MSC) certification scheme for fisheries is the most different from the CFRN framework because it lacks consideration of social and economic aspects. The paper thus raises the question of why fisheries management and certification continue to fall behind other sectors in the consideration of a broad spectrum of management objectives.

Drawing on recent applications of the Foucault-inspired governmentality approach to natural resources, Foley, Okyere and Mather (2018) conceptualize the CFRN's full-spectrum sustainability assessment framework as an innovative and progressive "technology of government" that is guided by an "environmentality" distinct from those guiding prominent auditing frameworks such as the MSC's certification standard for sustainable fisheries. Whereas the MSC's standard focuses on target fish stocks and ecosystem health, the CFRN includes consideration of social development principles and indicators. Although many critical analyses suggest that auditing frameworks inherently reflect and reinforce a neoliberal agenda, Foley et al. argue that the CFRN framework demonstrates how multiple objectives can manifest in audit culture, including social justice-oriented environmentalities in the governance of natural resources. Through an analysis of Canada's northern shrimp fishery, the first Canadian fishery certified by the MSC, they use several components of the CFRN's framework to identify critical social development objectives such as (i) the distribution of access and benefits, (ii) a focus on regional economic benefits, and (iii) the importance of labor and livelihoods. What emerges from the 
analysis is categories of information and social dynamics invisible to, and excluded from, MSC assessments of the same fishery. The authors argue that such information and knowledge_-including patterns of government decision making utilizing principles of equity in resource access, regional and community development benefits of resource use, and controversies over policy implementation and interpretation - can be of significant interest to decision makers, particularly in contexts where they have an interest in, or duty to consider, social impacts of policies.

Edwards and Pinkerton (2019) demonstrate the importance of considering multiple dimensions of ownership and control within a full-spectrum evaluation of fisheries management, in order to understand the full extent of these on the distribution of benefits. The hidden role of processor-controlled "holding licences" in the British Columbia halibut fishery is shown to be a major driver in the distribution of benefits, enabling processor control of where fishermen deliver their catch, and control of information fishermen receive about catch value. Although processors only own $\sim 10 \%$ of the halibut individual transferable quotas (ITQs), they control more than half of halibut quota leasing through their use of holding licences. Processors lease quota from investors early in the season, transfer the unfished quota to their holding licence, and then lease it out to fishermen throughout the season when fish is delivered to them. Processors are thus able to act as brokers between quota owners (investors who lease out quota) and quota lessees (fishermen who lease in quota) because of their access to capital and information about who will lease out quota at what price. New developments in ITQ leasing practices in the last decade have resulted in fishermen receiving no information on the landed value of their catch, but only information on what they receive, which may be less than the difference between the lease price and the landed value. This payment to fishermen can be adjusted by processors to transfer virtually all of the risk of leasing ITQs to lessee fishermen. Oligopsonistic practices are not new in the fishing industry: what is new about this practice is the extent of control and the secrecy surrounding the original lessor identity, the lease prices paid, and the landed value of the catch. The paper identifies remedial actions government could take to improve transparency and prevent price distortions.

Barnett (2018) engages the CFRN full-spectrum sustainability assessment framework through an analysis of a case study from Barrington, Nova Scotia, where fishing households and enterprises have become significantly dependent upon lobster in a context of changing species abundance and changing access relations. Barnett uses a survey of captains and fishing households connected to lobster fisheries to examine changing distribution of access and benefits and identifies perceptions of future access. Based on the results, Barnett suggests that the process of creating the Integrated Fisheries Management Plan (IFMP) for Canadian lobster (and more generally) would benefit from improved understanding of socioeconomic data on the distribution of benefits, livelihoods, and fishing strategies. Whether fishing captains can maintain their livelihoods, for example, depends not only on the price and quantity of their catch, but also on the costs of entering a fishery and on the means available to enter a fishery. Such costs can be influenced by time of entry, costs of entry, availability of credit, and informal and formal/contractual arrangements between fishers and harvesters that give corporations de facto control over owner-operator licences.
Barnett thus calls for IFMPs to incorporate mechanisms that are sensitive to the complex social, economic, and institutional challenges of the intergenerational transfer of fishing access rights in coastal communities where households, captains, and crew members interact in changing conditions. Such mechanisms, moreover, ought to be developed collaboratively and with interdisciplinary perspectives because of the challenges of complex data requirements and the risk of unintended consequences. Attaining equity and fairness in economic and financial conditions, and in health and well-being, need to be objectives that are reflected in the rules and decision-making processes.

Squires and Wiber (2018) explore how an expanding fish stock offered a rare opportunity to support fishing enterprises and communities when traditional fish stocks were diminished or had failed. The Eastern Nova Scotia (ENS) snow crab fishery is one example, where in 2005, a growing stock allowed benefit-sharing among more than 700 harvesters. As a contributing case study on social and institutional aspects of sustainability, Squires and Wiber review the background of that fishery and the outcomes of the redistribution of fishery benefits. Based on more than 50 semistructured interviews, the case study demonstrates how conflict both flared up and was ultimately resolved, with the fishery remaining biologically sound and highly beneficial. According to informants, the ENS snow crab rates quite highly on several sustainability measures. Stock productivity has remained strong, and other ecological aspects are accounted for within the IFMP. Under the socioeconomic domain of the CFRN framework, snow crab allocation greatly improved local economic stability for individual fishing enterprises and communities. Institutionally, a well-functioning industry advisory board has been created and contributes to operational details of the ENS fishery. Management is generally considered effective. Economically, the strong market for snow crab allocations indicates satisfaction with financial returns and confidence in future prospects. However, Squires and Wiber show how the method chosen to manage the distribution in Eastern Nova Scotia did not guarantee that benefits remained in local communities. Institutional arrangements (structure and process) allowed benefits to exit communities, thus affecting equity and fairness and access stability over the long run. The pooling of ENS snow crab allocations in core companies has led to problems as fishermen age out of the industry, with the company structure facilitating the separation of benefits from active fishing enterprises. Finally, unfettered allocation transferability contributes to escalating prices, with few new entrants acquiring snow crab allocations. This affects intergenerational equity and the right to a livelihood. Squires and Wiber compare this crab fishery with other jurisdictions, where alternative approaches developed in conjunction with broad-based harvester organizations demonstrated better benefit retention in local communities.

Open conflict represents a serious challenge in fisheries management and Parlee and Wiber (2018) argue that such conflict is inevitable given the plurality of actors, interests, values, and uses of marine space. Unresolved conflict may impede governance objectives and threaten the sustainability of social-ecological systems. In southwest New Brunswick, conflict between inshore fishermen and aquaculture operators led to an innovative 
institutional arrangement called the Southwest New Brunswick Bay of Fundy Marine Advisory Committee (MAC), a multistakeholder consultation process established in 2004 to both address conflict and to further marine planning. Parlee and Wiber draw on the experience of the MAC as a case study to explore potential governance measures for the CFRN sustainability framework. An assessment of the MAC experience offers significant lessons for advancing the theoretical approaches to good governance. Parlee and Wiber outline several lessons learned, including that such innovative governance needs to commit to a conflict resolution measure; allow for the possibility that overt forms of resistance may be an effective way forward; recognize that types of representation around the table can vary with significant impacts on outcome; provide communication plans for transparency and accountability to constituents; carefully monitor the role of government actors at the table; make explicit institutional or governance values and address value conflicts. Parlee and Wiber also conclude that, without explicit institutional indicators or measures of good governance such as conflict resolution, transparency and accountability cannot be assessed, or worse, may be traded off to achieve other objectives. In terms of the CFRN framework governance indicators, a weakness was identified in both the measure for transparency and the measure for inclusiveness. The framework allows users to assess whether there are mechanisms in place to ensure transparency and accountability. However, it focuses on the "what" question and is missing the "how" question. Therefore, to strengthen measures for transparency, Parlee and Wiber recommend that an indicator be added to examine how transparency and accountability criteria emerge, in addition to the shortcomings or assets of specific practices.

\section{LOOKING FORWARD: FUTURE CHALLENGES OF SUSTAINABILITY?}

To move beyond the application of overly simplistic and often harmful panaceas in fisheries management, this special feature joins recent efforts to develop comprehensive frameworks that can draw on the diverse knowledge of different perspectives and that are tested through context-sensitive case studies (e.g., Young et al. 2018). In developing and applying a full-spectrum sustainability framework, the research initiated by Project 1.1 of the Canadian Fisheries Research Network reveals insight about developing comprehensive approaches to sustainable fisheries evaluation in general and including often-neglected areas of governance institutions and the social development in such approaches in particular. The inclusion of governance and social considerations into research projects was spurred both by research into existing Canadian policy statements and by the active participation of social scientists, government scientists, and fishing industry representatives in research design workshops, a coconstruction approach in which the independent owneroperator sector of eastern Canada's small-scale fishery fleet played a central role. A key contribution of this special feature is thus highlighting the importance of governance/institutional processes (Parlee and Wiber 2018, Angel et al. 2019, Jones and Stephenson 2019) and the distribution of resource access and benefits (Barnett 2018, Foley et al. 2018, Squires and Wiber 2018, Edwards and Pinkerton 2019, Mussels and Stephenson 2020). Overall, the research experience reveals several overarching critical and ongoing challenges:
1. Interdisciplinary/transdisciplinary teams: Full-spectrum sustainability demands interdisciplinary or transdisciplinary approaches but, as others have noted (Turnhout et al. 2020), transdisciplinary and coproductive research is a major challenge because of institutional constraints, stove-piped/ siloed disciplinary cultures, power relations, and fragmented societal/industry values and interests.

2. Social considerations: Although access to, and distribution of, benefits is central to fisheries management, there is much work to be done to integrate diverse social considerations, such as health and safety, into applications of full-spectrum sustainability. There also still remains a long way to go in persuading many management agencies to give social aspects any significant attention. Although there has been increasing call for incorporation of social aspects, there remains a lack of definition, information, expertise, and use in management.

3. Governance considerations: Full-spectrum sustainability requires institutional structures and governance that can take a more holistic view. Such holistic views will be challenged to better account for conflicting interests and values, power relations, as well as challenges in participation, representation, transparency, and accountability.

4. Practical application: Future work is needed to move fullspectrum sustainability frameworks into more usable toolkits for different societal actors. In addition to the papers in this special feature, the CFRN framework has been useful in extending the perspective of the ecosystem approach to regional management in Canada's Department of Fisheries and Oceans (Daly, Bundy, and Stephenson, unpublished manuscript), as a lens for evaluation of fisheries management plans (Paul and Stephenson 2019), as a framework for practical integration of integrated management (Stephenson et al. 2019b), and to help shape the International Council for the Exploration of the Sea's Strategic Initiative on Human Dimensions, and Cumulative Effects Assessment Framework (ICES 2018, 2019). As others have noted for other frameworks, future practical applications could also be facilitated through the development of an online version that develops databases with hyperlinks, menus, and other tools that can be used by different organizations and decision makers (see discussion in Young et al. 2018).

This research on full-spectrum sustainability contributes to broader efforts at integrating human dimensions into sustainability assessments. Although the emergence of new approaches and fields such as sustainability science over the last two decades have begun to develop frameworks cutting across natural and social sciences and coconstructing knowledge with scientific communities and society (Kates et al. 2001), preparing the next generation of sustainability scientists requires better attention to the broader and fundamental social structures often overlooked in the field, including interests, power, and social change and overcoming practical challenges of university training, the development of team-science skills, and effectively integrating diverse stakeholder perspectives into research (Breslow et al. 2016, Killion et al. 2018, Olsson and Ness 2019). Creatively, collaboratively and proactively addressing diverse social-ecological challenges will become even more challenging 
in the future because of climate and ocean change (McDonald et al. 2019). Indeed, the United Nations has declared a Decade of Ocean Science for Sustainable Development (2021-2030) to gather ocean stakeholders worldwide behind a common framework that will ensure ocean science can reverse declines in ocean health, improve conditions for sustainable management of the ocean, and facilitate adaptation to ecosystem change (UNESCO 2019). Looking beyond this special feature, we propose the use of full-spectrum sustainability, including the four pillars identified by the Canadian Fisheries Research Network, as a useful tool in those efforts.

Responses to this article can be read online at: http://www.ecologyandsociety.org/issues/responses. php/11509

\section{Acknowledgments:}

The authors gratefully acknowledge the members of the Canadian Fisheries Research Network and its funders for the support and inspiration for this publication.

\section{Data Availability Statement:}

Datalcode sharing is not applicable to this article as no new datal code were created or analyzed in this study.

\section{LITERATURE CITED}

Angel, E., D. N. Edwards, S. Hawkshaw, C. Wor, and C. E. Parlee. 2019. An indicator framework to support comprehensive approaches to sustainable fisheries management. Ecology and Society 24(4):12. https://doi.org/10.5751/ES-11242-240412

Armitage, D. R., R. Plummer, F. Berkes, R. I. Arthur, A. T. Charles, I. J. Davidson-Hunt, A. P. Diduck, N. C. Doubleday, D. S. Johnson, M. Marschke et al. 2009. Adaptive co-management for social-ecological complexity. Frontiers in Ecology and the Environment 7(2):95-102. https://doi.org/10.1890/070089

Asche, F., and T. M. Garlock, J. L. Anderson, S. R. Bush, M. D. Smith, C. M. Anderson, J. Chu, K. A. Garrett, A. Lem, K. Lorenzen, A. Oglend, S. Tveteras, and S. Vannuccini. 2018. Three pillars of sustainability in fisheries. Proceedings of the National Academy of Sciences 115(44):11221-11225. https://doi.org/10.1073/ pnas. 1807677115

Barnett, A. J. 2018. Recommendations for full-spectrum sustainability in Canadian lobster integrated management plans based on a socioeconomic analysis of Barrington, Nova Scotia. Ecology and Society 23(1):36. https://doi.org/10.5751/ES-09981-230136

Bond, A. J., and A. Morrison-Saunders. 2011. Re-evaluating sustainability assessment: aligning the vision and the practice. Environmental Impact Assessment Review 31(1):1-7. https://doi. org/10.1016/j.eiar.2010.01.007

Breslow, S. J., B. Sojka, R. Barnea, X. Basurto, C. Carothers, S. Charnley, S. Coulthard, N. Dolšak, J. Donatuto, C. GarcíaQuijano, et al. 2016. Conceptualizing and operationalizing human wellbeing for ecosystem assessment and management.
Environmental Science \& Policy 66:250-259. https://doi. org/10.1016/j.envsci.2016.06.023

Brooks, K., J. Schirmer, S. Pascoe, L. Triantafillos, E. Jebreen, T. Cannard, and C. M. Dichmont. 2015. Selecting and assessing social objectives for Australian fisheries management. Marine Policy 53:111-122. https://doi.org/10.1016/j.marpol.2014.11.023

Chapin III, F. S., S. R. Carpenter, G. P., Kofinas, C. Folke, N. Abel, W. C. Clark, P. Olsson, D. M. Stafford Smith, B. Walker, O. R. Young, F. Berkes, R. Biggs, J. M. Grove, R. L. Naylor, E. Pinkerton, W. Steffen, and F. J. Swanson. 2010. Ecosystem stewardship: sustainability strategies for a rapidly changing planet. Trends in Ecology and Evolution 25(4):241-249. https://doi. org/10.1016/j.tree.2009.10.008

Charles, T., M. Wiber, K. Bigney, D. Curtis, L. Wilson, R. Angus, J. Kearney, M. Landry, M. Recchia, H. Saulnier, and C. White. 2010. Integrated management: a coastal community perspective. Horizons 10(4):26-34.

Chuenpagdee, R., and A. M. Song. 2012. Institutional thinking in fisheries governance: broadening perspectives. Current Opinion in Environmental Sustainability 4(3):309-315. https://doi. org/10.1016/j.cosust.2012.05.006

Dahl, A. L. 2012. Achievements and gaps in indicators for sustainability. Ecological Indicators 17:14-19. https://doi. org/10.1016/j.ecolind.2011.04.032

Davis, K., A. Fisher, B. Kingsbury, and S. Engle Merry. 2012. Governance by indicators: global power through quantification and rankings. Oxford University, Oxford, UK. https://doi. org/10.1093/acprof:oso/9780199658244.001.0001

Edwards, D. N., and E. Pinkerton. 2019. The hidden role of processors in an individual transferable quota fishery. Ecology and Society 24(3):36. https://doi.org/10.5751/ES-11148-240336

Elkington, J. 2013. Enter the triple bottom line. Pages 23-38 in A. Henriques and J. Richardson, editors. The triple bottom line. Routledge, New York, New York, USA.

Fletcher, W. J., J. Shaw, S. J. Metcalf, and D. J. Gaughan. 2010. An ecosystem based fisheries management framework: the efficient, regional-level planning tool for management agencies. Marine Policy 34:1226-1238. https://doi.org/10.1016/j.marpol.2010.04.007

Foley, P. 2013. National government responses to Marine Stewardship Council (MSC) fisheries certification: insights from Atlantic Canada. New Political Economy 18(2):284-307. https:// doi.org/10.1080/13563467.2012.684212

Foley, P. 2019. A Coxian perspective on transnational business governance interactions: counter-hegemonic certification movements in fisheries. Pages 294-314 in S. Wood, R. Schmidt, E. Meidinger, B. Eberlein, and K. W. Abbott, editors. Transnational business governance interactions: advancing marginalized actors and enhancing regulatory quality. Edward Elgar,Cheltenham, UK.

Foley, P., D. A. Okyere, and C. Mather. 2018. Alternative environmentalities: recasting the assessment of Canada's first Marine Stewardship Council-certified fishery in social terms. Ecology and Society 23(3):37. https://doi.org/10.5751/ES-10382-230337 
Food and Agriculture Organization (FAO). 2003. Fisheries management: the ecosystem approach to fisheries. Technical Guidelines for Responsible Fisheries 4(2):112.

Hicks, C., A. Levine, A. Agrawal, X. Basurto, S. J. Breslow, C. Carothers, S. Charnley, S. Coulthard, N. Dolsak, J. Donatuto, C. Garcia-Quijano, M. B. Mascia, K. Norman, M. R. Poe, T. Satterfield, K. St. Martin, and P. S. Levin. 2016. Engage key social concepts for sustainability. Science 352(6281):38-40. https://doi. org/10.1126/science.aad4977

International Council for the Exploration of the Sea (ICES). 2018. Report of the SIHD workshop on balancing economic, social, and institutional objectives in integrated assessments (WKSIHD$B E S I O)$. ICES, Copenhagen, Denmark.

International Council for the Exploration of the Sea (ICES). 2019. Working group on cumulative effects assessment approaches in management (WGCEAM). ICES, Copenhagen, Denmark. http://doi.org/10.17895/ices.pub.5759

Jacquet, J. L., and D. Pauly. 2007. The rise of seafood awareness campaigns in an era of collapsing fisheries. Marine Policy 31 (3):308-313. https://doi.org/10.1016/j.marpol.2006.09.003

Jentoft, S., and R. Chuenpagdee. 2009. Fisheries and coastal government as a wicked problem. Marine Policy 33(4):553-560. https://doi.org/10.1016/j.marpol.2008.12.002

Jones, O. P., and R. L. Stephenson. 2019. Practical use of fullspectrum sustainability in the Bay of Fundy. Ecology and Society 24(3):25. https://doi.org/10.5751/ES-11010-240325

Kates, R. W., W. C. Clark, R. Corell, J. M. Hall, C. C. Jaeger, I. Lowe, J. J. McCarthy, H. J. Schellnhuber, B. Bolin, N. M. Dickson, et al. 2001. Sustainability science. Science 292(5517):641-642. https://doi.org/10.1126/science.1059386

Kates, R. W., T. M. Parris, and A. A. Leiserowitz. 2005. What is sustainable development? Goals, indicators, values, and practice. Environment: Science and Policy for Sustainable Development 47 (3):8-21. https://doi.org/10.1080/00139157.2005.10524444

Killion, A. K., K. Sterle, E. Bondank, J. Drabik, A. Bera, S. Alian, K. Goodrich, M. Hale, R. A. Myer, Q. Phung, A. M. Shew, and A. W. Thayer. 2018. Preparing the next generation of sustainability scientists. Ecology and Society 23(4):39. https://doi. org/10.5751/ES-10395-230439

Kittinger, J. N., L. C. L. Teh, E. H. Allison, N. J. Bennett, L. B. Crowder, E. M. Finkbeiner, C. Hicks, C. G. Scarton, K. Nakamura, Y. Ota, et al. 2017. Committing to socially responsible seafood. Science 356(6341):912-913. https://doi.org/10.1126/ science.aam9969

Kofinas, G. P., and F. S. Chapin III. 2009. Sustaining livelihoods and human well-being during social-ecological change. Pages 55-75 in C. Folke, G. P. Kofinas, and F. S. Chapin, editors. Principles of ecosystem stewardship: resilience-based natural resource management in a changing world. Springer, New York, New York, USA. https://doi.org/10.1007/978-0-387-73033-2 3

Konefal, J. 2013. Environmental movements, market-based approaches, and neoliberalization: a case study of the sustainable seafood movement. Organization \& Environment 26(3):336-352. https://doi.org/10.1177/1086026612467982
Lélé, S. M. 1991. Sustainable development: a critical review. World Development 19(6):607-621. https://doi.org/10.1016/0305-750X (91)90197-P

Levin, P. S., S. J. Breslow, C. J. Harvey, K. C. Norman, M. R. Poe, G. D. Williams, and M. L. Plummer. 2016. Conceptualization of social-ecological systems of the California current: an examination of interdisciplinary science supporting ecosystembased management. Coastal Management 44(5):397-408. https:// doi.org/10.1080/08920753.2016.1208036

McDonald, K. S., A. J. Hobday, P. A. Thompson, A. Lenton, R. L. Stephenson, B. D. Mapstone, L. X. C. Dutra, C. Bessey, F. Boschetti, C. Cvitanovic, et al. 2019. Proactive, reactive, and inactive pathways for scientists in a changing world. Earth's Future 7(2):60-73. https://doi.org/10.1029/2018EF000990

Meadowcroft, J. 2000. Sustainable development: a new (ish) idea for a new century? Political Studies 48(2):370-387. https://doi. org/10.1111/1467-9248.00265

Micheli, F., G. De Leo, G. G. Shester, R. G. Martone, S. E. LluchCota, C. Butner, L. B. Crowder, R. Fujita, S. Gelcich, et al. 2014. A system-wide approach to supporting improvements in seafood production practices and outcomes. Frontiers in Ecology and the Environment 12(5):297-305. https://doi.org/10.1890/110257

Millennium Ecosystem Assessment. 2005. Ecosystems and human well-being: synthesis. Island, Washington, D.C., USA.

Mussells, C., and R. L. Stephenson. 2020. A comparison of sustainability objectives: how well does the Canadian Fisheries Research Network framework compare with fisheries, forestry, and aquaculture certification schemes? Ecology and Society 25 (1):17. https://doi.org/10.5751/ES-11368-250117

Olsson, L., and B. Ness. 2019. Better balancing the social and natural dimensions in sustainability research. Ecology and Society 24(4):7. https://doi.org/10.5751/ES-11224-240407

Ommer, R. 2000. Just fish: ethics and Canadian marine fisheries. Institute of Social and Economic Research, Memorial University, St. John's, Newfoundland, Canada.

Ommer, R. E., I. R. Perry, G. Murray, and B. Neis. 2012. Socialecological dynamism, knowledge, and sustainable coastal marine fisheries. Current Opinion in Environmental Sustainability 4 (3):316-322. https://doi.org/10.1016/j.cosust.2012.05.010

Ostrom, E., and M. Cox. 2010. Moving beyond panaceas: a multitiered diagnostic approach for social-ecological analysis. Environmental Conservation 37(4):451-463. https://doi.org/10.1017/ S0376892910000834

Parkes, G., J. A. Young, S. F. Walmsley, R. Abel, J. Harman, P. Horvat, A. Lem, A. MacFarlane, M. Mens, and C. Nolan. 2010. Behind the signs - a global review of fish sustainability information schemes. Reviews in Fisheries Science 18(4):344-356. https://doi.org/10.1080/10641262.2010.516374

Parlee, C. E., and M. G. Wiber. 2018. Using conflict over risk management in the marine environment to strengthen measures of governance. Ecology and Society 23(4):5. https://doi. org/10.5751/ES-10334-230405

Paul, S. D., and R. L. Stephenson. 2019. The integration of fullspectrum ecosystem-based management in Canadian fisheries 
management plans. Canadian Technical Report of Fisheries and Aquatic Sciences 3350, Fisheries and Oceans Canada Science Branch, Maritimes Region, St. Andrews, New Brunswick, Canada.

Pinkerton, E. 2003. Toward specificity in complexity: understanding co-management from a social science perspective. Pages 61-77 in D. C. Wilson, J. R. Nielsen, and P. Degnbol, editors. The fisheries co-management experience: accomplishments, challenges and prospects. Springer, Dordrecht, The Netherlands. https://doi.org/10.1007/978-94-017-3323-6

Pinkerton, E., E. Angel, N. Ladell, P. Williams, M. Nicolson, J. Thorkelson, and H. Clifton. 2014. Local and regional strategies for rebuilding fisheries management institutions in coastal British Columbia: what components of comanagement are most critical? Ecology and Society 19(2):72. https://doi.org/10.5751/ES-06489-190272

Pinkerton, E., and R. Davis. 2015. Neoliberalism and the politics of enclosure in North American small-scale fisheries. Marine Policy 61:303-312. https://doi.org/10.1016/j.marpol.2015.03.025

Pintér, L., P. Hardi, A. Martinuzzi, and J. Hall. 2012. Bellagio STAMP: principles for sustainability assessment and measurement. Ecological Indicators 17:20-28. https://doi. org/10.1016/j.ecolind.2011.07.001

Plummer, R., D. R. Armitage, and R. C. de Loë. 2013. Adaptive comanagement and its relationship to environmental governance. Ecology and Society 18(1):21. https://doi.org/10.5751/ES-05383-180121

Plummer, R., B. Crona, D. Armitage, P. Olsson, M. Tengö, and O. Yudina. 2012. Adaptive comanagement: a systematic review and analysis. Ecology and Society 17(3):11. https://doi. org/10.5751/ES-04952-170311

Ponte, S. 2012. The Marine Stewardship Council (MSC) and the making of a market for 'sustainable fish.' Journal of Agrarian Change 12(2-3):300-315. https://doi.org/10.1111/j.1471-0366.2011.00345. $\underline{\mathrm{X}}$

Squires, K., and M. G. Wiber. 2018. Distribution of fishery benefits and community well-being: a review of increased access to the Eastern Nova Scotia snow crab fishery. Ecology and Society 23(2):25. https://doi.org/10.5751/ES-10137-230225

Stephenson, R. L., A. J. Benson, K. Brooks, A. Charles, P. Degnbol, C. M. Dichmont, M. Kraan, S. Pascoe, S. D. Paul, A. Rindorf, and M. Wiber. 2017. Practical steps toward integrating economic, social and institutional elements in fisheries policy and management. ICES Journal of Marine Science 74(7):1981-1989. https://doi.org/10.1093/icesjms/fsx057

Stephenson, R. L., A. J. Hobday, C. Cvitanovic, K. A. Alexander, G. A. Begg, R. H. Bustamante, P. K. Dunstan, S. Frusher, M. Fudge, E. A. Fulton, M. Haward, C. Macleod, J. McDonald, K. L. Nash, E. Ogier, G. Pecl, É. E. Plagányi, I. van Putten, T. Smith, and T. M. Ward. 2019b. A practical framework for implementing and evaluating integrated management of marine activities. Ocean and Coastal Management 177:127-138. URL: https://doi. org/10.1016/j.ocecoaman.2019.04.008

Stephenson R. L., S. Paul, M. Wiber, E. Angel, A. J. Benson, A. Charles, O. Chouinard, M. Clemens, D. Edwards, P. Foley, L. Jennings, O. Jones, D. Lane, J. McIsaac, C. Mussells, B. Neis, B.
Nordstrom, C. Parlee, E. Pinkerton, M. Saunders, K. Squires, and U. R. Sumaila. 2018. Evaluating and implementing socialecological systems: a comprehensive approach to sustainable fisheries. Fish and Fisheries 19(5):853-873. https://doi. org/10.1111/faf.12296

Stephenson, R. L., M. Wiber, S. Paul, E. Angel, A. Benson, A. Charles, O. Chouinard, D. Edwards, P. Foley, D. Lane, J. McIsaac, B. Neis, C. Parlee, E. Pinkerton, M. Saunders, K. Squires, and U. R. Sumaila. 2019a. Integrating diverse objectives for sustainable fisheries in Canada. Canadian Journal of Fisheries and Aquatic Sciences 76(3):480-496. https://doi.org/10.1139/cjfas-2017-0345

Symes, D., and E. Hoefnagel. 2010. Fisheries policy, research and the social sciences in Europe: challenges for the 21 st century. Marine Policy 34(2):268-275. https://doi.org/10.1016/j.marpol.2009.07.006

Thompson, S. A., R. L. Stephenson, G. A. Rose, and S. D. Paul. 2019. Collaborative fisheries research: the Canadian Fisheries Research Network experience. Canadian Journal of Fisheries and Aquatic Sciences 76(5):671-681. https://doi.org/10.1139/cjfas-2018-0450

Triantafillos, L., K. Brooks, J. Schirmer, S. Pascoe, T. Cannard, C. Dichmont, O. Thebaud, and E. Jebreen. 2014. Developing and testing social objectives for fisheries management. Fisheries Research and Development Corporation Report - Project 2010/040. Primary Industries and Regions, South Australia, Adelaide. [online] URL: https://www.frdc.com.au/ArchivedReports/FRDC\%20Projects/2010-040-DLD.pdf

Turnhout, E., T. Metze, C. Wyborn, N. Klenk, and E. Louder. 2020. The politics of co-production: participation, power, and transformation. Current Opinion in Environmental Sustainability 42:15-21. https://doi.org/10.1016/j.cosust.2019.11.009

UNESCO. 2019. United Nations decade of ocean science for sustainable development (2021-2030). UNESCO, Paris, France. [online] URL: https://en.unesco.org/ocean-decade

United Nations. 2018. The sustainable development agenda. United Nations, New York, New York, USA. [online] URL: https://www.un.org/sustainabledevelopment/development-agenda/

Urquhart, J., T. Acott, and M. Zhao. 2013. Introduction: social and cultural impacts of marine fisheries. Marine Policy 37:1-2. https://doi.org/10.1016/j.marpol.2012.04.007

Witter, A., and J. Stoll. 2017. Participation and resistance: alternative seafood marketing in a neoliberal era. Marine Policy 80:130-140. https://doi.org/10.1016/j.marpol.2016.09.023

Young, O. R., D. G. Webster, M. E. Cox, J. Raakjær, L. Ø. Blaxekjær, N. Einarsson, R. A. Virginia, J. Acheson, D. Bromley, E. Cardwell, C. Carothers, E. Eythórsson, R. B. Howarth, S. Jentoft, B. J. McCay, F. McCormack, G. Osherenko, E. Pinkerton, R. van Ginkel, J. A. Wilson, L. Rivers III, and R. S. Wilson. 2018. Moving beyond panaceas in fisheries governance. Proceedings of the National Academy of Sciences 115(37):9065-9073. https://doi. org/10.1073/pnas.1716545115 